\title{
Static Model-Based Assessment of OATP1B1-Mediated Drug Interactions with Preincubation-Dependent Inhibitors Based on Inactivation and Recovery Kinetics ${ }^{\mathbb{S}}$
}

\author{
Takayuki Taguchi, Yusuke Masuo, Azusa Futatsugi, and Yukio Kato \\ Pharmacokinetics and Safety Department, Drug Research Center, Kaken Pharmaceutical Co., Ltd., Kyoto, Japan (T.T.) and Faculty \\ of Pharmacy, Institute of Medical, Pharmaceutical and Health Sciences, Kanazawa University, Kanazawa, Japan (T.T., Y.M., \\ A.F., Y.K.)
}

Received March 18, 2020; accepted June 23, 2020

\begin{abstract}
Quantitative assessment of drug-drug interactions (DDIs) via organic anion transporting polypeptide (OATP) 1B1 is one of the key issues in drug development. Although OATP1B1 inhibition exhibits unique characteristics, including preincubation dependence for some inhibitors, a limited approach has been attempted based on the static model that considers such preincubation dependence in the prediction of DDIs via OATP1B1. The present study aimed to establish the prediction of DDIs via OATP1B1 using preincubationdependent inhibitors based on the static model and incorporating both inactivation and recovery of OATP1B1 activity. Cyclosporine A was selected as a preincubation-dependent inhibitor, as well as five substrates that include probes and pharmaceuticals. The inhibition ratio ( $R$ value) calculated on the basis of a conventional static model, considering inhibition of OATP1B1 and contribution ratio of OATP1B1 to the overall hepatic uptake, was much lower than the reported AUC ratio, even when ${ }^{\prime C} C_{50}$ values were estimated after preincubation conditions. Conversely, the $\mathbf{R}$ value that was estimated by considering
\end{abstract}

\section{Introduction}

In the pharmaceutical industry, drug-drug interactions (DDIs) are a major concern during drug development. DDIs alter systemic exposure of the victim drug, resulting in unwanted clinical outcomes, such as severe side effects and a decrease in therapeutic efficacy. Therefore, it is important to evaluate potential DDIs for new chemical entities (NCEs). During the early drug developmental stage, this evaluation is often performed based on the so-called static model, which principally incorporates inhibition potential to target enzymes of NCEs designated as $\mathrm{IC}_{50}$ values and the maximum unbound NCE concentration plausibly exposed to humans. This approach could be valuable to avoid falsenegative predictions of DDIs induced by competitive inhibition of drugmetabolizing enzymes and transporters. However, its application to the perpetrator drugs, which may potentially exhibit time-dependent enzyme inhibition, should be carefully examined.

This work was financed by Kaken Pharmaceutical Co., Ltd https://doi.org/10.1124/dmd.120.000020.

S This article has supplemental material available at dmd.aspetjournals.org. inactivation and recovery parameters was closer to the AUC ratio. The $R$ value that was calculated assuming the complete contribution of OATP1B1 was much higher than the AUC ratio, avoiding false-negative prediction. The $\mathbf{R}$ value estimated by considering inactivation and recovery for another combination of a preincubation-dependent inhibitor, asunaprevir, and substrate drug, rosuvastatin, was also closer to the AUC ratio. Thus, $R$ values calculated based on such OATP1B1 kinetics would be potential alternative indexes for the quantitative prediction of OATP1B1-mediated DDIs using preincubation-dependent inhibitors, although this prediction is affected by estimation of the contribution ratio of substrates.

\section{SIGNIFICANCE STATEMENT}

Static model-based quantitative prediction of organic anion transporting polypeptide 1B1-mediated drug-drug interactions induced by preincubation-dependent inhibitors was newly proposed to avoid false-negative prediction.

ABBREVIATIONS: AUC, area under the curve; CsA, cyclosporine A; DDI, drug-drug interaction; $\mathrm{E}_{2} \mathrm{G}$, estradiol-17 $\beta$-glucuronide; $\mathrm{E}_{1} \mathrm{~S}$, estrone 3sulfate; $\mathrm{f}_{\mathrm{u}, \mathrm{p}}$, unbound fraction in plasma; $\mathrm{HCV}$, hepatitis $\mathrm{C}$ virus; $\mathrm{HEK}$, human embryonic kidney; $\mathrm{I}_{\mathrm{u} \text {,inlet,max }}$, maximum unbound concentration of perpetrators in the inlet of the liver; NCE, new chemical entity; OATP, organic anion transporting polypeptide; $\mathrm{R}$ value, inhibition ratio; TKI, tyrosine kinase inhibitor. 
(Izumi et al., 2015; Shitara and Sugiyama, 2017), and these may be relevant to the obstacles in predicting DDIs based on in vitro studies. Previously, cyclosporine A (CsA), human immunodeficiency virus protease inhibitors, direct-acting antihepatitis $\mathrm{C}$ virus (HCV) agents, and tyrosine kinase inhibitors (TKIs) have exhibited the preincubationdependent inhibition of OATP1B1 (Shitara et al., 2013; Furihata et al., 2014; Pahwa et al., 2017; Taguchi at al., 2019). Furthermore, CsA, HCV agents, and pazopanib have also been reported as long- or short-lasting inhibitors (Shitara et al., 2013; Furihata et al., 2014; Taguchi at al., 2019). Although the so-called dynamic model has been recently proposed for the long-lasting inhibition of OATP1B1 by CsA (Shitara and Sugiyama 2017), a direct inhibition-based conventional static model is recommended to be considered in the prediction of DDIs via OATP1B1. Moreover, a systematic assessment of the interaction between CsA and the OATP substrate pravastatin has been performed in rats, revealing that this interaction appears to be long-lasting and can be described by the static model with the apparent $\mathrm{IC}_{50}$ value for unbound CsA more than 1000 times lower than that experimentally measured in vitro in isolated rat hepatocytes ((Taguchi et al., 2016)). Thus, the prediction based on a simple static model incorporating direct inhibition alone is not applicable for DDIs mediated by OATP1B1 inhibition by preincubation-dependent inhibitors.

In the present study, we attempted to investigate another approach for the prediction of OATP1B1-mediated DDIs with preincubationdependent inhibitors. Physiologically based pharmacokinetic model analysis is useful for the quantitative prediction of DDIs, although it is sometimes complex and takes more time compared with the static model-based analysis. Therefore, we focused on the static model-based approach. We proposed $\mathrm{R}$ values that consider not only $\mathrm{IC}_{50}$ and $\mathrm{I}_{\mathrm{u} \text {,inlet,max }}$ values but also the inactivation and recovery kinetics of OATP1B1 activity and contribution ratio of OATP1B1 to the overall hepatic uptake of the victim drugs. As a perpetrator drug, cyclosporine A was first selected because abundant in vitro information is available that demonstrates its long-lasting inhibition, as well as clinical data regarding DDIs via OATP1B1 induced by this drug. In the present study, the original concept of the prediction strategy was deduced from the kinetic analysis of time-dependent inhibition of the metabolic enzyme; to the best of our knowledge, there has been no report on its application to OATP1B1. Here, typical OATP1B1 substrates were used as victim drugs to validate the approach because substrate-dependent OATP1B1 inhibition has been reported (Izumi et al., 2015). Furthermore, the inhibition potential of other preincubation-dependent inhibitor drugs of OATP1B1, such as anti-HCV agents and TKIs, was also examined.

\section{Materials and Methods}

Materials. CsA and atorvastatin calcium trihydrate were purchased from FUJIFILM Wako Pure Chemical (Tokyo, Japan). Asunaprevir was procured from Santa Cruz Biotechnology (Dallas, TX), nilotinib was from ChemScene, LLC (Monmouth Junction, NJ), regorafenib was from Toronto Research Chemicals (North York, ON), pazopanib was from Synkinase Pvt Ltd (Victoria, Australia), pitavastatin calcium was from Avachem Scientific (San Antonio, TX), and rosuvastatin calcium was from AK Scientific (Union City, CA). $\left[{ }^{3} \mathrm{H}\right]$ Estrone 3sulfate $\left(\mathrm{E}_{1} \mathrm{~S}\right)$ and $\left[{ }^{3} \mathrm{H}\right]$ estradiol-17 $\beta$-glucuronide $\left(\mathrm{E}_{2} \mathrm{G}\right)$ were obtained from PerkinElmer (Waltham, MA). All other reagents were of analytical grade.

Cell Culture. HEK293 cells stably expressing OATP1B1 (HEK293/ OATP1B1 cells) and the vector alone (HEK293/mock) were constructed as previously described ((Fujita et al., 2014)). HEK293/OATP1B1 cells were routinely grown in culture medium consisting of Dulbecco's modified Eagle's medium (high glucose) without L-glutamine and phenol red (FUJIFILM Wako Pure Chemical) and containing $10 \%$ fetal bovine serum, penicillin, streptomycin, and $1 \mathrm{mg} / \mathrm{ml} \mathrm{G} 418$ in a humidified incubator at $37^{\circ} \mathrm{C}$ and $5 \% \mathrm{CO}_{2}$. For the transport studies, HEK293/OATP1B1 and HEK293/mock cells were seeded in 24-well plates (Becton Dickinson, Franklin Lakes, NJ) coated with poly-D-lysine
(R\&D Systems, Minneapolis, MN) at a density of $1.0 \times 10^{5}$ cells per well and cultured in the culture medium. After 2 days, $5 \mu 1$ of $500 \mathrm{mM}$ sodium butyrate was added to the medium for the induction of OATP1B1 expression to obtain a final concentration of $5 \mathrm{mM}$. The following preincubation-dependent inhibition, inactivation, and recovery studies were started 1 day after the addition of butylate.

Preincubation-Dependent Inhibition Study. The cells were washed twice with the transport buffer $\left(125 \mathrm{mM} \mathrm{NaCl}, 4.8 \mathrm{mM} \mathrm{KCl}, 1.2 \mathrm{mM} \mathrm{CaCl}_{2}, 1.2 \mathrm{mM}\right.$ $\mathrm{KH}_{2} \mathrm{PO}_{4}, 1.2 \mathrm{mM} \mathrm{MgSO}$, $35 \mathrm{mM}$ HEPES, and $5.6 \mathrm{mM}$ D-glucose, $\left.\mathrm{pH} 7.4\right)$ prewarmed at $37^{\circ} \mathrm{C}$ and pretreated for 5 minutes with the transport buffer without substrates or inhibitors. The medium was then replaced with the transport buffer containing the vehicle alone ( $1 \%$ dimethyl sulfoxide) or inhibitors at various concentrations, and cells were further preincubated for the designated period at $37^{\circ} \mathrm{C}$. After preincubation, the transport buffer containing the vehicle alone or inhibitors was removed, and the reaction was then started by applying prewarmed fresh transport buffer containing each OATP1B1 substrate and inhibitor to the cells. At 0.5 minutes $\left(\left[{ }^{3} \mathrm{H}\right] \mathrm{E}_{1} \mathrm{~S}\right.$ and $\left.\left[{ }^{3} \mathrm{H}\right] \mathrm{E}_{2} \mathrm{G}\right)$ or 1 minute (atorvastatin, pitavastatin, and rosuvastatin), the reaction solution was removed by aspiration, and cells were washed twice with ice-cold transport buffer.

Inactivation Study for OATP1B1 Activity. The cells were washed twice with the prewarmed transport buffer at $37^{\circ} \mathrm{C}$. After pretreatment for 5 minutes with the transporter buffer alone, HEK293/OATP1B1 cells were preincubated with the transport buffer containing the vehicle control (1\% dimethyl sulfoxide) or inhibitors at the designated concentrations (CsA, 0.05-0.5 $\mu \mathrm{M}$; asunaprevir, 0.05-1 $\mu \mathrm{M}$; nilotinib, 0.2-5 $\mu \mathrm{M}$; regorafenib, 1-10 $\mu \mathrm{M}$; pazopanib, $0.1-2 \mu \mathrm{M}$ ) for the designated period (CsA, 20 seconds to 3 minutes; asunaprevir, 1-5 minutes; nilotinib, 1-5 minutes; regorafenib, 5-30 minutes; pazopanib, 0.5-2 minutes) at $37^{\circ} \mathrm{C}$. This period was designed to be appropriate for chasing OATP1B1 inactivation by each compound. After preincubation, the cells were washed once with the prewarmed transport buffer without inhibitors to minimize the effect of inhibitors remaining in the reaction solution; the prewarmed transport buffer containing OATP1B1 substrates without inhibitors was then immediately applied. At 0.5 or 1 minute, the reaction solution was removed by aspiration, and cells were washed twice with ice-cold transport buffer.

Recovery Study for OATP1B1 Activity. The medium was replaced with fresh culture medium containing the inhibitors, followed by preincubation with the inhibitors for $30(\mathrm{CsA})$ or 60 (asunaprevir, nilotinib, regorafenib, and pazopanib) minutes. Next, the medium was again replaced with the culture medium without inhibitors, and the cells were cultured for the designated period (0-2 hours for CsA and 0-15 minutes for asunaprevir, nilotinib, regorafenib, and pazopanib) to recover OATP1B1 activity. This period was designed to be appropriate for chasing recovery of OATP1B1 activity after preincubation with each compound. Notably, the culture medium, not the transport buffer, was used in the preincubation and recovery phase because of the prolonged incubation period ( $\sim 2.5$ hours). Then, the cells were washed once with the prewarmed transport buffer, and the uptake study was immediately started by replacing the medium with the transport buffer containing each OATP1B1 substrate alone. At 0.5 or 1 minute, cells were washed twice with the ice-cold transport buffer.

Determination of Cell-Associated Radioactivity. The cells were solubilized with $0.2 \mathrm{ml}$ of $0.2 \mathrm{~N} \mathrm{NaOH}$ overnight, followed by neutralization with $\mathrm{HCl}$. Cell lysates and the reaction solution were then mixed with a scintillation fluid, and radioactivity was measured with a liquid scintillation analyzer (Tricarb 4910TR; PerkinElmer). The cellular protein content was determined according to the Bradford method using a protein assay kit (Bio-Rad Laboratories, Hercules, CA), with bovine serum albumin as the standard.

Estimation of the Unbound Fraction in Plasma. Human plasma was obtained from eight volunteers in accordance with the Declaration of Helsinki and approval from the Kaken Research Ethics Committee, and a mixture of their plasma was used. The unbound fraction $\left(\mathrm{f}_{\mathrm{u}, \mathrm{p}}\right)$ of CsA in human plasma was determined by the equilibrium dialysis method. Dialysis membranes (pore diameter of $5 \mathrm{~nm}, 14,000$-Da molecular mass cutoff) were soaked for 1 hour in distilled water and set to the equilibrium dialysis device (Sekisui medical, Tokyo, Japan). A 750- $\mu 1$ aliquot of the plasma and buffer samples was placed in the opposing reservoirs separated by a dialysis membrane and dialyzed at $37^{\circ} \mathrm{C}$ for 20 hours. The concentrations of CsA in the dialysates were determined using liquid chromatography-mass spectrometry.

Liquid Chromatography-Tandem Mass Spectrometry Analysis. To analyze the cell-associated amount of the unlabeled compound (atorvastatin, pitavastatin, and rosuvastatin), the cells were recovered by cell scraper and 
disrupted in distilled water with a sonicator. The pretreatment of this sample and dialysates obtained in equilibrium dialysis was performed as described previously ((Yoshimatsu et al., 2016)). Quantification of CsA, atorvastatin, pitavastatin, and rosuvastatin was performed using TSQ QUANTUM Vantage mass spectrometer (ThermoFisher Scientific) coupled to a liquid chromatography system (NANOAPACE NASCA2 5200) (Shiseido, Tokyo, Japan). Liquid chromatography conditions for CsA were as follows: Capcell Pak C18 (3- $\mu \mathrm{m}$ particle size, $1.5 \mathrm{~mm}$ inner diameter $\times 35 \mathrm{~mm}$; Shiseido); column temperature, $40^{\circ} \mathrm{C}$; step-gradient elution [0-0.6 minutes, $85 \%$ A/15\% B; 0.6-2.8 minutes, $5 \%$ A/95\% B; $2.8-4.6$ minutes, $0 \% \mathrm{~A} / 100 \% \mathrm{~B} ; 4.6-7.5$ minutes, $85 \% \mathrm{~A} / 15 \% \mathrm{~B}$ (A, $1 \mathrm{mM}$ ammonium acetate; $\mathrm{B}$, acetonitrile)]; flow rate (0-3.7 minutes, $0.4 \mathrm{ml} / \mathrm{min}$; $3.7-4.6$ minutes, $0.6 \mathrm{ml} / \mathrm{min}$; 4.6-7.5 minutes, $0.4 \mathrm{ml} / \mathrm{min}$ ), and injection volume, $10 \mu \mathrm{l}$. Liquid chromatography conditions for atorvastatin, pitavastatin, and fluvastatin were as follows: YMC-Triart C18 $(5-\mu \mathrm{m}$ particle size, $2.0 \mathrm{~mm}$ inner diameter $\times 50 \mathrm{~mm}$; YMC, Kyoto); column temperature, $40^{\circ} \mathrm{C}$; step-gradient elution [0-0.6 minutes, $85 \% \mathrm{~A} / 15 \% \mathrm{~B} ; 0.6-2.8$ minutes, $5 \% \mathrm{~A} / 95 \% \mathrm{~B} ; 2.8-4.6$ minutes, $0 \% \mathrm{~A} / 100 \% \mathrm{~B}$; 4.6-7.5 minutes, $85 \% \mathrm{~A} / 15 \% \mathrm{~B}$ (A, $0.1 \%$ formic acid; $\mathrm{B}$, methanol)]; flow rate (0-3.7 minutes, $0.4 \mathrm{ml} / \mathrm{min}$; $3.7-4.6$ minutes, $0.6 \mathrm{ml} / \mathrm{min}$; $4.6-7.5$ minutes, $0.4 \mathrm{ml} / \mathrm{min}$ ), and injection volume, $10 \mu \mathrm{l}$. The parameters for the mass spectrometer were as follows: electrospray ionization; spray voltage, $3500 \mathrm{~V}$; capillary temperature, $330^{\circ} \mathrm{C}$; multiple reaction monitoring method with transitions of $m / z, 1202.9 \rightarrow 425.3$ for CsA, $m / z, 422.3 \rightarrow 274.1$ for pitavastatin, and $\mathrm{m} / z 531.2 \rightarrow 243.9$ for ketoconazole (internal standard) in the positive ion mode and $\mathrm{m} / \mathrm{z}, 557.3 \rightarrow 278.2$ for atorvastatin and $\mathrm{m} / \mathrm{z} 480.2 \rightarrow 418.2$ for rosuvastatin in the negative ion mode. Validation of the bioanalytical methods is shown in Supplemental Table 1.

Data Analysis. OATP1B1-mediated uptake was calculated by subtraction of the uptake observed in HEK293/mock cells from that in HEK293/OATP1B1 cells. Concentration-dependent inhibition of uptake was fitted to the following equation to estimate the $\mathrm{IC}_{50}$ values:

$$
\mathrm{V}_{\text {control }} / \mathrm{V}_{\text {inhibitor }}=\mathrm{IC}_{50}^{\gamma} /\left(\mathrm{I}^{\gamma}+\mathrm{IC}_{50}^{\gamma}\right)
$$

where $\mathrm{V}_{\text {control }}$ and $\mathrm{V}_{\text {inhibitor }}$ are the uptake of the substrate in the absence and presence of inhibitor, respectively, I is the inhibitor concentration, and $\gamma$ is Hill's coefficient.

In the inactivation study, the natural logarithm of percent remaining activity was plotted against the preincubation period for each inhibitor concentration. The slope from the linear regression analysis presented the apparent first-order inactivation rate constant $\left(\mathrm{k}_{\mathrm{obs}, \mathrm{app}}\right)$ for each concentration. Then, $\mathrm{k}_{\mathrm{obs}, \mathrm{app}}$ and I were fitted to the following equation to estimate the $\mathrm{k}_{\text {inact }}$ and $\mathrm{K}_{\mathrm{I}}$ values:

$$
\mathrm{k}_{\mathrm{obs}, \text { app }}=\mathrm{k}_{\text {inact }} \times \mathrm{I} /\left(\mathrm{K}_{\mathrm{I}}+\mathrm{I}\right)
$$

where $k_{\text {inact }}$ is the maximal inactivation rate constant, and $K_{I}$ is the inhibitor concentration causing half-maximal inactivation. The damping Gauss-Newton method algorithm was used with a MULTI program to perform nonlinear leastsquares data fitting ((Yamaoka et al., 1981)).

Estimation of $\mathbf{R}$ Values. The inhibitory potential of a perpetrator drug on OATP1B1 activity was first calculated by estimating the $\mathrm{R}_{0}$ value as follows:

$$
\begin{gathered}
\mathrm{R}_{0}=1 /\left(\left(1 / \mathrm{R}_{0}^{\prime}\right) \times \mathrm{f}+(1-\mathrm{f})\right) \\
\mathrm{R}_{0}^{\prime}=1+\mathrm{I}_{\mathrm{u}, \text { inlet,max }} / \mathrm{K}_{\mathrm{i}}
\end{gathered}
$$

where $\mathrm{f}$ represents the contribution ratio of OATP1B1-mediated uptake to overall hepatic uptake of victim drug. $\mathrm{K}_{\mathrm{i}}$ represents the inhibition constant and was assumed to be equal to $\mathrm{IC}_{50}$ values because the concentration of the substrate was much lower than the relevant $\mathrm{K}_{\mathrm{m}}$ value (see Supplemental Table 2). These $\mathrm{IC}_{50}$ values were estimated without preincubation. $\mathrm{I}_{\mathrm{u} \text {,inlet,max }}$ was calculated using the following equation (Ito et al., 1998):

$$
\mathrm{I}_{\mathrm{u}, \text { inlet,max }}=\mathrm{f}_{\mathrm{u}, \mathrm{p}} \times\left(\mathrm{I}_{\max }+\left(\mathrm{k}_{\mathrm{a}} \times \mathrm{F}_{\mathrm{a}} \mathrm{F}_{\mathrm{g}} \times \text { Dose }\right) / \mathrm{Q}_{\mathrm{h}} / \mathrm{R}_{\mathrm{B}}\right)
$$

where $\mathrm{I}_{\max }$ is the maximum systemic plasma concentration, $\mathrm{k}_{\mathrm{a}}$ is the absorption rate constant, $\mathrm{F}_{\mathrm{a}} \mathrm{F}_{\mathrm{g}}$ is the fraction of the dose that is absorbed, Dose is the dose of the perpetrator, $Q_{h}$ is hepatic blood flow, and $R_{B}$ is the blood-to-plasma concentration ratio. Thus, the estimation of $R_{0}$ values was based on the static model considering maximum competitive/noncompetitive inhibition potential without preincubation.
To predict the OATP1B1-mediated DDIs by preincubation-dependent inhibitors, the $\mathrm{IC}_{50}$ values experimentally estimated after preincubation with the inhibitor were used to estimate the $R$ values based on eqs. 3 and 4. These $R$ values were designated as $R_{1}$ and $R_{1}{ }^{\prime}$ values. Then, the following $R_{2}$ and $R_{3}$ values were also proposed in the present study:

$$
\begin{gathered}
\mathrm{R}_{2}=1 /\left(\left(1 / \mathrm{R}_{2}^{\prime}\right) \times \mathrm{f}+(1-\mathrm{f})\right) \\
\mathrm{R}_{2}^{\prime}=\left(\mathrm{k}_{\text {obs }}+\mathrm{k}_{\text {recovery }}\right) / \mathrm{k}_{\text {recovery }} \\
\mathrm{k}_{\text {obs }}=\mathrm{k}_{\text {inact }} \times \mathrm{I}_{\mathrm{u}, \text { inlet,max }} /\left(\mathrm{K}_{\mathrm{I}}+\mathrm{I}_{\mathrm{u}, \text { inlet,max }}\right)
\end{gathered}
$$

where $\mathrm{k}_{\mathrm{obs}}$ is the inactivation rate constant, and $\mathrm{k}_{\text {recovery }}$ is apparent first-order recovery rate constant. Estimation of the $\mathrm{R}_{2}$ value considered inactivation and recovery of OATP1B1 activity and was based on kinetic analysis of timedependent inhibition (Mayhew et al., 2000):

$$
\begin{gathered}
\mathrm{R}_{3}=1 /\left(\mathrm{A}_{\mathrm{h}} \times \mathrm{B}_{\mathrm{h}} \times \mathrm{f} \times(1-\mathrm{f})\right) \\
\mathrm{A}_{\mathrm{h}}=1 /\left(1+\mathrm{I}_{\mathrm{u}, \text { inlet,max }} / \mathrm{IC}_{50, \text { pre }(-)}\right) \\
\mathrm{B}_{\mathrm{h}}=\mathrm{k}_{\text {recovery }} /\left(\mathrm{k}_{\text {obs }}+\mathrm{k}_{\text {recovery }}\right)
\end{gathered}
$$

where $A_{h}$ and $B_{h}$ denote direct (competitive or noncompetitive) inhibition and preincubation-dependent inactivation, respectively, and $\mathrm{IC}_{50, \text { pre(-) }}$ is $\mathrm{IC}_{50}$ estimated without preincubation with perpetrators. Thus, $\mathrm{R}_{3}$ includes both direct and preincubation-dependent inhibition (Fahmi et al., 2009). The $\mathrm{R}_{1}{ }^{\prime}, \mathrm{R}_{2}{ }^{\prime}$, and $\mathrm{R}_{3}{ }^{\prime}$ values were thus $R_{1}, R_{2}$, and $R_{3}$ values when the $f$ value was assumed to be unity (OATP1B1 solely contributes to hepatic uptake of victim drug) where

$$
\mathrm{R}_{3}^{\prime}=1 /\left(\mathrm{A}_{\mathrm{h}} \times \mathrm{B}_{\mathrm{h}}\right)
$$

The $\mathrm{R}$ values, means, and S.E. values were calculated using Microsoft Excel 2013

\section{Results}

Preincubation-Dependent Inhibition by CsA of OATP1B1Mediated Uptake of Various Substrates. The preincubation period with CsA was first fixed as 30 minutes because in our previous studies, this period was sufficient to investigate potential preincubationdependent OATP1B1 inhibition by this compound using $\left[{ }^{3} \mathrm{H}\right] \mathrm{E}_{1} \mathrm{~S}$ as an OATP1B1 substrate (Taguchi et al., 2019). The OATP1B1-mediated uptake of five substrates was examined and was reduced after preincubation with CsA for 30 minutes when compared with the nopreincubation condition (Fig. 1). The $\mathrm{IC}_{50}$ values of CsA after 30 minutes of preincubation were 4.7- to 11-fold lower than those without preincubation and were comparable among the five substrates examined (0.02-0.05 $\mu \mathrm{M}$, Table 1). The $\mathrm{IC}_{50}$ values and fold change were comparable with the previously reported values for CsA after preincubation for 1 hour (0.01-0.07 $\mu \mathrm{M}$ and 4.5- to 9.6-fold, respectively) when $\mathrm{E}_{1} \mathrm{~S}, \mathrm{E}_{2} \mathrm{G}$, atorvastatin, and pitavastatin were used as substrates (Izumi et al., 2015).

Inactivation Profile of OATP1B1 Activity by Preincubation with CsA. Next, OATP1B1 activity remaining after preincubation with CsA was assessed using the uptake study of each OATP1B1 substrate. OATP1B1 activity assessed as the uptake of all the five substrates examined was reduced by preincubation with CsA in a concentrationdependent manner (Fig. 2). In the case of uptake of $\left[{ }^{3} \mathrm{H}\right] \mathrm{E}_{1} \mathrm{~S},\left[{ }^{3} \mathrm{H}\right] \mathrm{E}_{2} \mathrm{G}$, pitavastatin, and rosuvastatin, the OATP1B1 activity rapidly declined during preincubation with CsA for 20 seconds and did not linearly decline up to 1 minute (Fig. 2, A, B, D, and E). Conversely, the OATP1B1 activity assessed as the uptake of atorvastatin almost linearly declined with up to 3 minutes of the preincubation, at least at lower concentrations of CsA (Fig. 2C). Based on these kinetics of OATP1B1 activity inactivation, the $\mathrm{k}_{\text {obs,app }}$ values were then estimated from the slope of the remaining OATP1B1 activity (Fig. 2). Because of difficulty in preincubating for a period shorter than 20 seconds, the $\mathrm{k}_{\mathrm{obs} \text {,app }}$ was calculated from the slope of the remaining OATP1B 1 activity at 0 and 20 

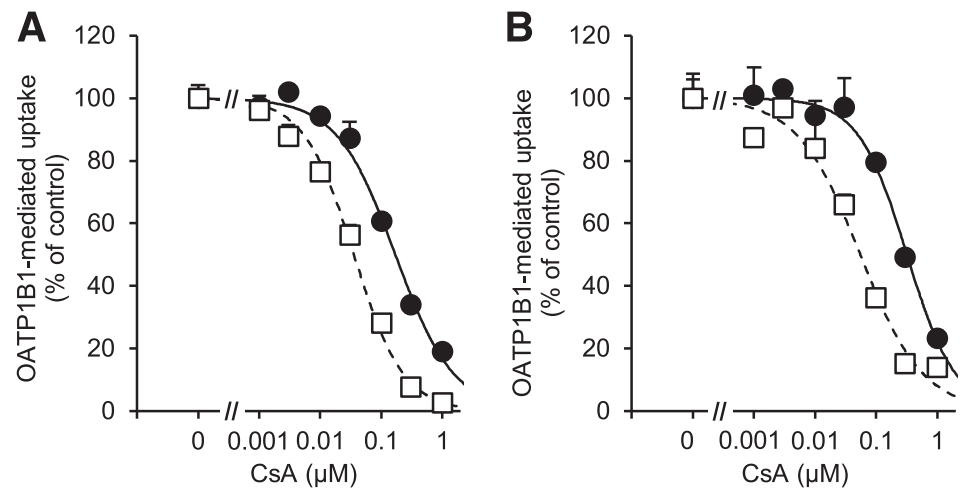

0 min

(without preincubation)

$\square 30 \mathrm{~min}$

A $E_{1} S$

$B E_{2} G$

C Atorvastatin

D Pitavastatin

E Rosuvastatin
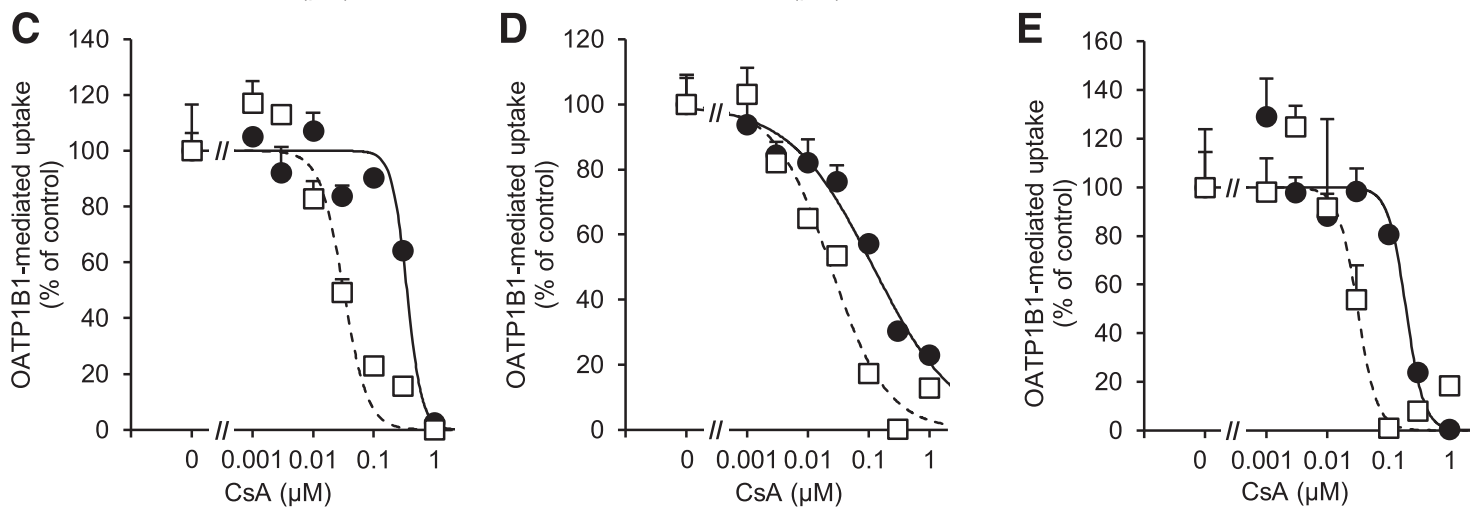

Fig. 1. Inhibition of OATP1B1-mediated uptake of $\left[{ }^{3} \mathrm{H}\right] \mathrm{E}_{1} \mathrm{~S}(\mathrm{~A}),\left[{ }^{3} \mathrm{H}\right] \mathrm{E}_{2} \mathrm{G}(\mathrm{B})$, atorvastatin $(\mathrm{C})$, pitavastatin (D), and rosuvastatin (E) after preincubation with CsA. The cells were washed with transport buffer prewarmed at $37^{\circ} \mathrm{C}$ and were then pretreated for 5 minutes with the transport buffer without substrates or inhibitors. The medium was then replaced with the transport buffer containing inhibitors at the various concentrations of $\mathrm{CsA}$, and cells were further preincubated for 0 or 30 minutes at $37^{\circ} \mathrm{C}$. After the preincubation, the transport buffer containing inhibitors was removed, and the reaction was then started by applying prewarmed fresh transport buffer containing [ $\left.{ }^{3} \mathrm{H}\right] \mathrm{E}_{1} \mathrm{~S}$, $\left[{ }^{3} \mathrm{H}\right] \mathrm{E}_{2} \mathrm{G}$, atorvastatin $(0.3 \mu \mathrm{M})$, pitavastatin $(0.5 \mu \mathrm{M})$, or rosuvastatin $(3 \mu \mathrm{M})$ and the inhibitors to the cells. At 0.5 minutes $\left({ }^{3} \mathrm{H}\right] \mathrm{E}_{1} \mathrm{~S}$ and $\left.\left[{ }^{3} \mathrm{H}\right] \mathrm{E}_{2} \mathrm{G}\right)$ or 1 minute $($ atorvastatin, pitavastatin, and rosuvastatin), the reaction solution was removed by aspiration, and cells were washed with ice-cold transport buffer. The OATP1B1-mediated uptake was obtained by subtracting the uptake in HEK293/mock cells from that in HEK293/OATP1B1 cells. Data are shown as percentage mean uptake volume values \pm S.E. of three to six wells in one to two independent experiments compared with those of the control.

seconds for the uptake of $\left[{ }^{3} \mathrm{H}\right] \mathrm{E}_{1} \mathrm{~S},\left[{ }^{3} \mathrm{H}\right] \mathrm{E}_{2} \mathrm{G}$, pitavastatin, and rosuvastatin. The $\mathrm{k}_{\mathrm{obs}, \mathrm{app}}$ for atorvastatin uptake was calculated as the slope from the linear regression analysis until 3 minutes. The observed $\mathrm{k}_{\mathrm{obs}, \mathrm{app}}$ values were plotted versus the concentration of CsA preincubated (Fig. 3), and both $k_{\text {inact }}$ and $K_{I}$ values were calculated based on eq. 2 (Table 1).

Recovery of OATP1B1 Activity after Preincubation with CsA. After preincubation with CsA for 30 minutes, HEK293/OATP1B1 cells were washed and cultured for the designated period without CsA or substrates, and the uptake of OATP1B1 substrates was then examined in the absence of the inhibitor. Immediately after preincubation with 0.3 $\mu \mathrm{M}$ CsA, OATP1B1-mediated uptake of $\left[{ }^{3} \mathrm{H}\right] \mathrm{E}_{1} \mathrm{~S},\left[{ }^{3} \mathrm{H}\right] \mathrm{E}_{2} \mathrm{G}$, atorvastatin, pitavastatin, and rosuvastatin was reduced to $26 \%, 29 \%, 18 \%, 36 \%$, and $57 \%$ of the control, respectively (Fig. 4). The reduced OATP1B1 activity was recovered in a culture period-dependent manner (Fig. 4), and the $\mathrm{k}_{\text {recovery }}$ value was calculated using linear regression analysis (Table 1).

Assessment of OATP1B1-Mediated DDI Potential with CsA Based on the Static Model Incorporating Inactivation and Recovery of OATP1B1 Activity. Static model-based assessment of OATP1B1-mediated DDI potential was next performed for three OATP1B1 substrates, for which the AUC ratio with or without the coadministration of CsA was clinically reported. First, the $\mathrm{f}_{\mathrm{u}, \mathrm{p}}$ value (0.0107) of CsA was evaluated by equilibrium dialysis in-house, whereas the $\mathrm{I}_{\mathrm{u}, \text { inlet,max }}$ value of CsA was calculated by eq. 5 using pharmacokinetic parameters summarized in Supplemental Table 3 (Table 1). Contribution ratio (f value) of OATP1B1-mediated uptake to overall uptake of the three OATP1B1 substrates in human hepatocytes was estimated as the average of previously reported values (Kunze et al., 2014; Izumi et al., 2018; Zhang et al., 2019) (Table 1). The $\mathrm{R}_{0}$ values of CsA without consideration of the preincubation effect were first calculated by eq. 3 for the five OATP1B1 substrates and were close to unity (Table 1), suggesting that direct inhibition of OATP1B1 by CsA does not present a clinical impact. Then, $\mathrm{R}_{1}$ values were next calculated using $\mathrm{IC}_{50}$ values estimated after 30 minutes of preincubation with CsA and were higher than $R_{0}$ values (Table 1 ). However, the $R_{1}$ values calculated for the three OATP1B1 substrate drugs remained considerably lower than the observed AUC ratio (Table 1). In contrast, the $R_{2}$ and $R_{3}$ values calculated by eqs. 6 and 9 , respectively, were higher than the $R_{1}$ values and closer to the observed AUC ratio (Table 1). To estimate the maximum potential of OATP1B1-mediated DDI, the $\mathrm{R}^{\prime}$ values were also estimated when OATP1B1 alone was assumed to contribute to the overall hepatic uptake of each substrate (the $f$ value was considered to be unity). Thus, The $R_{1}{ }^{\prime}$ values estimated were comparable with the $R_{1}$ values and lower than the AUC ratios. On the other hand, $R_{2}{ }^{\prime}$ and $R_{3}{ }^{\prime}$ values were markedly higher than the $R_{2}$ and $R_{3}$ values and the AUC ratio clinically reported (Table 1 ).

Estimation of OATP1B1-Mediated DDI Potential by PreincubationDependent Inhibitors Other than CsA. It was previously reported that the inhibition of OATP1B1 by compounds other than CsA, including simeprevir, asunaprevir, and ritonavir, was increased by preincubation with the respective compounds (Shitara et al., 2013; Furihata et al., 2014), although the enhanced OATP1B1 inhibition was not remarkable when compared with CsA. Furthermore, many TKIs strongly inhibit 


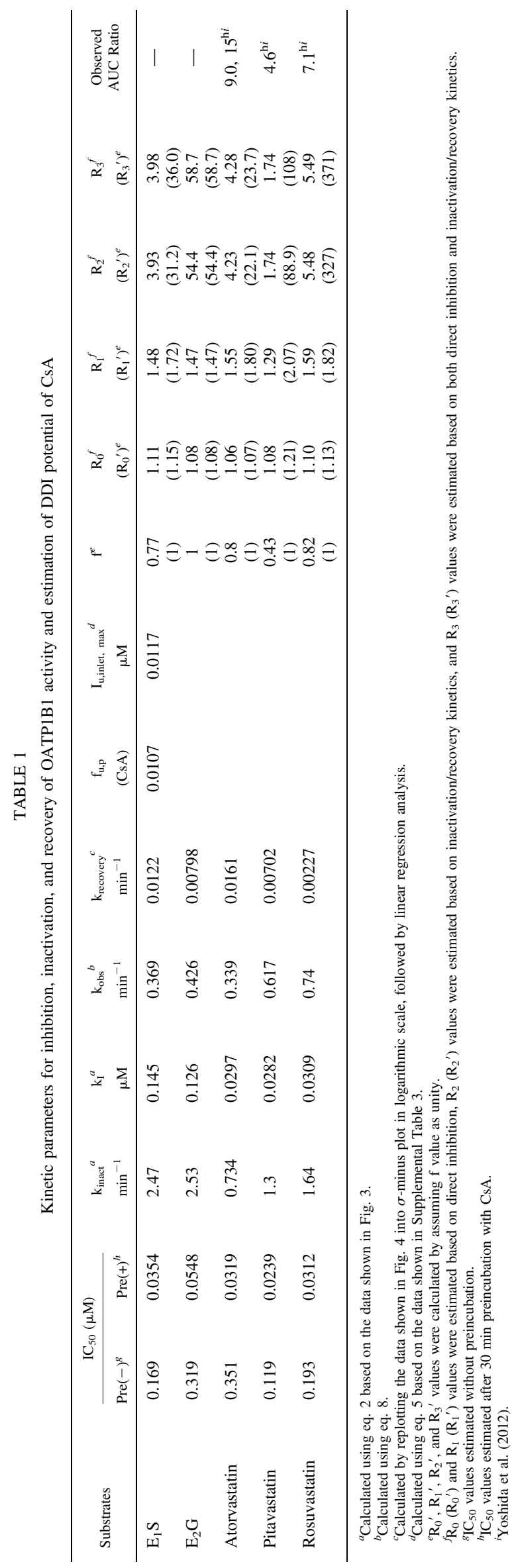

OATP1B1 after preincubation for 15 minutes ((Sprowl et al., 2016)), with details regarding the effects of such preincubation on their inhibitory potential not presented in the report. To investigate the potential preincubation-dependent OATP1B1 inhibition by these compounds, inhibition studies were conducted with or without preincubation with the compounds in the present study. Preincubation for 30 minutes with all investigated inhibitors reduced the OATP1B1-mediated uptake of $\left[{ }^{3} \mathrm{H}\right] \mathrm{E}_{1} \mathrm{~S}$ when compared with that observed without preincubation (Fig. 5). Among the inhibitors, asunaprevir, regorafenib, nilotinib, and pazopanib were selected for further evaluation of their potential for OATP1B1-mediated DDI. Inhibition, inactivation, and recovery after preincubation with these compounds were then examined with CsA (Supplemental Figs. 1-3). In the case of asunaprevir, OATP1B1mediated uptake was decreased in a concentration-dependent manner with and without preincubation, the inhibition being more potent after preincubation for longer than 30 minutes (Supplemental Fig. 1). In contrast, the inhibition of OATP1B1-mediated uptake by regorafenib and nilotinib without preincubation was only minimal (25\% and $17 \%$ of control, respectively), even at $10 \mu \mathrm{M}$ (Supplemental Fig. 1), whereas inhibition was evident when the cells were preincubated with these compounds (Supplemental Fig. 1). The $\mathrm{IC}_{50}$ values of regorafenib and nilotinib can be estimated only with preincubation longer than 30 minutes and 1 minute, respectively (Supplemental Table 4).

The pharmacokinetic parameters of these inhibitors obtained from the literature (Supplemental Table 3) were used to estimate the $\mathrm{R}$ values based on inactivation and recovery kinetics of OATP1B1 activity examined in the present study. The $\mathrm{R}_{0}{ }^{\prime}$ values were close to unity, whereas the $\mathrm{R}_{1}{ }^{\prime}, \mathrm{R}_{2}{ }^{\prime}$, and $\mathrm{R}_{3}{ }^{\prime}$ values of regorafenib and nilotinib were at most $1.2-1.3$. The $\mathrm{R}_{2}{ }^{\prime}$ and $\mathrm{R}_{3}{ }^{\prime}$ values of pazopanib were approximately 2 (Table 2). In the case of asunaprevir, a clinical DDI study with rosuvastatin was previously conducted, and the $\mathrm{R}$ value was calculated using the contribution ratio of OATP1B1 to overall hepatic uptake for rosuvastatin (Table 1 ). In this combination, the $R_{0}$ and $R_{1}$ values were lower, but the $R_{2}$ and $R_{3}$ values were close to the observed AUC ratio (Table 2).

\section{Discussion}

The avoidance of false-negative predictions in the case of DDIs via OATP1B1 is one of the most critical standpoints in patient safety during drug development. Inhibition of OATP1B1 by several drugs exhibits preincubation dependence, which could potentially lead to the falsenegative prediction of their DDI potential. Here, we attempted to construct a static model for the prediction of OATP1B1-mediated DDIs induced by preincubation-dependent inhibitors by considering not only $\mathrm{IC}_{50}$ values and $\mathrm{I}_{\mathrm{u} \text {,inlet,max }}$ of perpetrators but also the inactivation and recovery kinetics of OATP1B1 activity. The rationale of this proposal could be explained by the $\mathrm{R}_{1}$ values of $\mathrm{CsA}$ and asunaprevir calculated using $\mathrm{IC}_{50}$ values estimated after preincubation being lower than the observed AUC ratios (Tables 1 and 2), indicating that the false-negative prediction of DDI potential cannot be avoided, even when we performed preincubation using in vitro transport studies to estimate the $\mathrm{IC}_{50}$ values.

CsA is a preincubation-dependent OATP1B1 inhibitor with abundant clinical DDI information. Therefore, the inhibition, inactivation, and recovery studies using $\mathrm{CsA}$ as a typical inhibitor were first conducted to validate the approach in the present study. The $\mathrm{R}_{1}$ values of CsA for the three OATP1B1 substrates were much lower than the observed AUC ratios, whereas the $R_{2}$ and $R_{3}$ values for the three OATP1B1 substrates were closer to the observed AUC ratios (Table 1). A similar tendency was also observed for the $\mathrm{R}_{1}, \mathrm{R}_{2}$, and $\mathrm{R}_{3}$ values for another combination of DDI (asunaprevir versus rosuvastatin, Table 2), suggesting that the $R_{2}$ and $R_{3}$ values were better indexes for the quantitative prediction of 

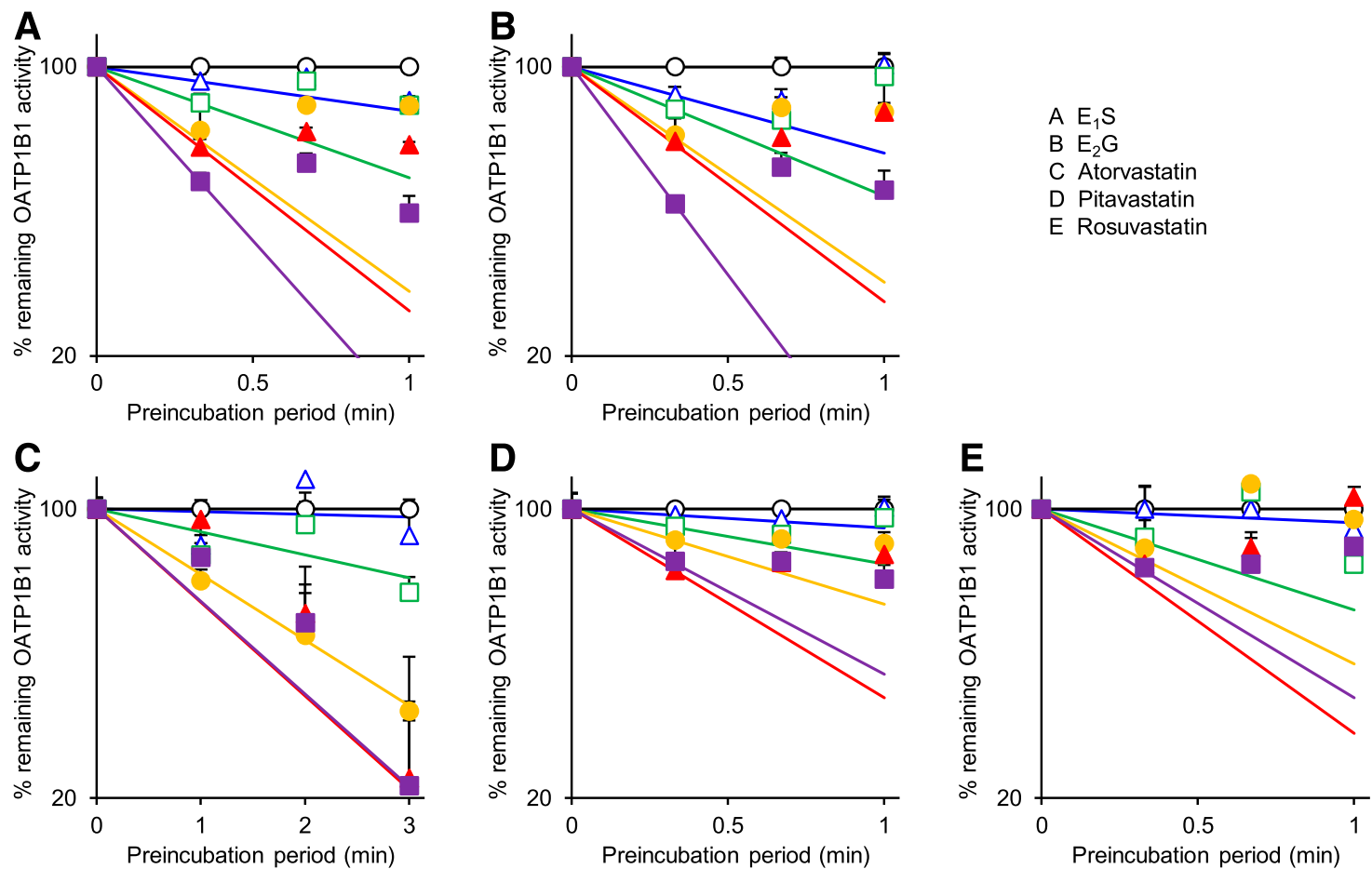

Fig. 2. Inactivation of OATP1B1-mediated uptake of $\left[{ }^{3} \mathrm{H}\right] \mathrm{E}_{1} \mathrm{~S}(\mathrm{~A}),\left[{ }^{3} \mathrm{H}\right] \mathrm{E}_{2} \mathrm{G}(\mathrm{B})$, atorvastatin (C), pitavastatin (D), and rosuvastatin (E) after preincubation with CsA HEK293/OATP1B1 cells were preincubated with CsA at $0\left(\mathrm{O}\right.$, black), $0.02\left(\triangle\right.$, blue), 0.05 ( $\square$, green), $0.1\left(\bullet\right.$, orange), $0.2\left(\boldsymbol{\Delta}\right.$, red), and $0.5 \mu \mathrm{M}\left(\mathbf{\bullet}\right.$, purple) for $\left[{ }^{3} \mathrm{H}\right] \mathrm{E}_{1} \mathrm{~S}$ and $\left[{ }^{3} \mathrm{H}\right] \mathrm{E}_{2} \mathrm{G}$ and $0(\mathrm{O}$, black), $0.005(\triangle$, blue $), 0.01(\square$, green), $0.02(\boldsymbol{\bullet}$, orange), $0.05(\boldsymbol{\Lambda}$, red), and $0.1 \mu \mathrm{M}(\boldsymbol{\bullet}$, purple) for atorvastatin, pitavastatin, and rosuvastatin for the designated periods. After preincubation, the cells were washed once with prewarmed transport buffer and incubated with each substrate. At $0.5\left(\left[{ }^{3} \mathrm{H}\right] \mathrm{E}_{1} \mathrm{~S}\right.$ and $\left.\left[{ }^{3} \mathrm{H}\right] \mathrm{E}_{2} \mathrm{G}\right)$ or 1 minute (atorvastatin, pitavastatin, and rosuvastatin), the reaction solution was aspirated, and the cells were washed twice with ice-cold transport buffer, followed by determination of their uptake. Uptake values are represented as the percentage of the activity obtained in the vehicle control samples and are plotted vs. the preincubation period. Each symbol represents the mean \pm S.E. of three wells in a single experiment.

OATP1B1-mediated DDI. Since the $\mathrm{R}_{2}$ and $\mathrm{R}_{3}$ values consider inactivation and recovery kinetics of OATP1B1 activity during preincubation with the inhibitors, these results suggest the utility of the static model incorporating such OATP1B1 kinetics for predicting DDIs induced by preincubation-dependent inhibitors. It should be noted, however, that precise estimation of the inactivation and recovery kinetics with a sufficient amount of data would be critical for the DDI's prediction in this strategy.

However, the $R_{2}$ and $R_{3}$ values for CsA and the three OATP1B1 substrates were lower than the observed AUC ratio (Table 1), demonstrating the underprediction of DDIs. The static model proposed in the present study only considered OATP1B1-mediated DDI, whereas clinical DDIs with CsA may involve inhibition of not only OATP1B1 but also other metabolizing enzymes and/or transporters. Then, one of the possible reasons could be the inhibition by CsA of other metabolic pathways and/or transporters rather than OATP1B1. Actually, CsA is an inhibitor of OATP1B3, breast cancer resistance protein, and CYP3A4 (Duan et al., 2017). Another possible reason for the lower $R_{2}$ and $R_{3}$ values when compared with the AUC ratio would be the estimation of the $f$ value. The estimation of the $R$ values $\left(R_{1}, R_{2}\right.$, and $\left.R_{3}\right)$ is affected by the $f$ values (eqs. 3,6 , and 9), and the $f$ values used in the present study represented the average of reported values and may exhibit experimental/interindividual variability, which may affect the accuracy of the $\mathrm{R}$ values. From this perspective, other types of $\mathrm{R}$ values $\left(\mathrm{R}_{1}{ }^{\prime}, \mathrm{R}_{2}{ }^{\prime}\right.$, and $\left.\mathrm{R}_{3}{ }^{\prime}\right)$ were also estimated by assuming an $\mathrm{f}$ value of unity in the present study. These $\mathrm{R}$ values may be valid to avoid false-negative DDI predictions since OATP1B1 alone was assumed to be involved in the hepatic uptake of each substrate. $\mathrm{R}_{2}{ }^{\prime}$ and $\mathrm{R}_{3}{ }^{\prime}$ values were higher than the observed AUC ratio (Tables 1 and 2), showing overestimation but no falsenegative DDI predictions. This would be beneficial in terms of the maximum DDI potential via OATP1B1 through the inhibitor compounds examined. Therefore, the present strategy using the $\mathrm{R}_{2}{ }^{\prime} / \mathrm{R}_{3}{ }^{\prime}$ values may be valuable when the maximum DDI potential for candidate compounds is estimated in the preclinical stage of drug development. However, it should be noted that the difference between the $\mathrm{R}_{2}{ }^{\prime} / \mathrm{R}_{3}{ }^{\prime}$ values and the observed AUC ratio was substantial, especially for the combination of CsA versus pitavastatin and rosuvastatin (Table 1). Higher $\mathrm{k}_{\text {inact }}$ and lower $\mathrm{k}_{\text {recovery }}$ values were observed for these two substrates (Table 1), indicating larger inactivation with slower recovery of OATP1B1 activity. Thus, the precise estimation of DDI potential for the inhibitors showing such a remarkable effect on the turnover of OATP1B1 activity could be hindered by the estimation of the f values.

The approach proposed in the present study has mainly focused on avoidance of false-negative prediction, but it should be noted that this may concomitantly increase the false-positive rate. Therefore, avoidance of false-negative prediction of DDIs should also be achieved by building the necessary margins and/or simulating the worst-case scenarios by construction of a dynamic model, such as a physiologically based pharmacokinetic model.

In the present study, various inhibitors other than CsA were found to exhibit the preincubation-dependent inhibition of OATP1B1 (Fig. 5). Therefore, the kinetics of inactivation and recovery of OATP1B1 activity was also examined for some of these inhibitors. Notably, the inhibition of OATP1B1 by regorafenib and nilotinib was apparent only when the HEK293/OATP1B1 cells were preincubated with these compounds (Supplemental Fig. 1), indicating the importance of the preincubation step in the estimation of the maximum inhibition potential for specific types of OATP1B1 inhibitors. However, the R' values for these two compounds were at most 1.2-1.3 (Table 2), suggesting their limited OATP1B1-mediated DDI potential even when inactivation 

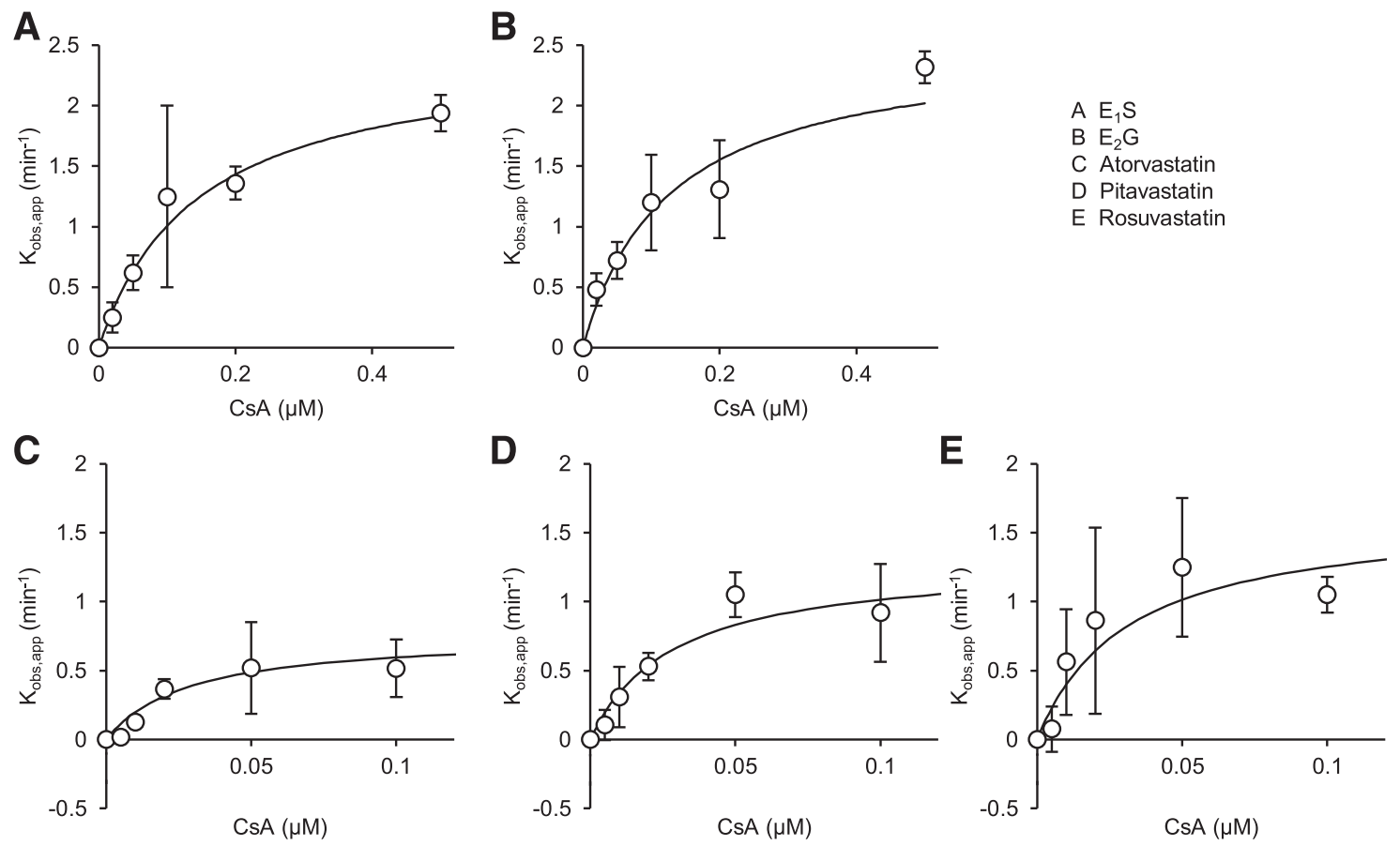

Fig. 3. Observed $k_{\text {obs,app }}$ values of OATP1B1-mediated uptake of $\left.\left[{ }^{3} \mathrm{H}\right] \mathrm{E}_{1} \mathrm{~S}(\mathrm{~A}),{ }^{3} \mathrm{H}\right] \mathrm{E}_{2} \mathrm{G}(\mathrm{B})$, atorvastatin (C), pitavastatin (D), and rosuvastatin (E) vs. CsA concentration. The $k_{\text {obs,app }}$ values were determined as the negative slopes of the natural logarithm $\left(0-20\right.$ seconds for $\left[{ }^{3} \mathrm{H}\right] \mathrm{E}_{1} \mathrm{~S},\left[{ }^{3} \mathrm{H}\right] \mathrm{E}_{2} \mathrm{G}$, pitavastatin, and rosuvastatin; $0-3$ minutes for atorvastatin) shown in Fig. 2. Solid lines represent the fitting curves of the observed $\mathrm{k}_{\mathrm{obs}, \mathrm{app}}$ vs. CsA concentration by nonlinear regression analysis based on eq. 2 . Each symbol represents the mean \pm S.E. of three wells in a single experiment.

and recovery kinetics were considered. On the other hand, pazopanib exhibited larger $R_{2}$ and $R_{3}$ values because of its higher $k_{o b s}$ value (Table 2). Although coadministration of pazopanib was reported to increase the AUC of the OATP1B1 substrate SN-38 (Bennouna et al., 2015), this interaction was proposed to be accounted for primarily through the inhibition of glucuronidation of SN-38 by pazopanib (Iwase et al., 2019). Regarding asunaprevir, Eley et al. (2015) have proposed that this compound is a weak OATP inhibitor, showing a 1.41-fold increase in the AUC of rosuvastatin, which seemed comparable with the $R_{2}$ and $R_{3}$ values estimated in the present study (Table 2).

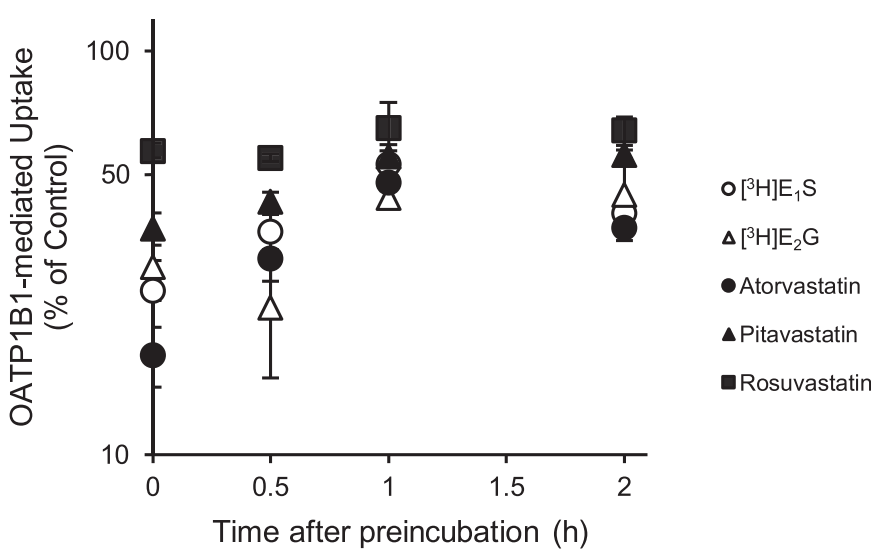

Fig. 4. Recovery of OATP1B1 activity after preincubation with CsA. HEK293/ OATP1B1 cells were preincubated with culture medium containing CsA $(0.3 \mu \mathrm{M})$ for 30 minutes. The medium was replaced with fresh culture medium and further incubated in the absence of CsA for the designated periods. The cells were then washed with prewarmed transport buffer once, and the transport buffer, including $\left[{ }^{3} \mathrm{H}\right] \mathrm{E}_{1} \mathrm{~S}(\mathrm{O}),\left[{ }^{3} \mathrm{H}\right] \mathrm{E}_{2} \mathrm{G}(\triangle)$, atorvastatin $(\bullet)$, pitavastatin $(\boldsymbol{\Delta})$, and rosuvastatin (•), was added, followed by determination of their uptake. Data are normalized with the control value obtained without the inhibitor and are shown as means \pm S.E. of three wells in a single experiment.
Izumi et al. (2015) have reported that, after 1 hour of preincubation, the $\mathrm{IC}_{50}$ values of CsA reported approximately a 6-fold difference among the five OATP1B1 substrates examined (Izumi et al., 2015). In the present study, the kinetics of inactivation and recovery of OATP1B1 activity induced by CsA was further evaluated for several OATP1B1 substrates and was found to also be substrate-dependent (Figs. 2-4). Both $\mathrm{k}_{\text {inact }}$ and $\mathrm{k}_{\text {recovery }}$ values of CsA were found to exhibit a three-toseven-times difference among the substrates (Table 1). Therefore, to predict the DDI potential based on the static model proposed in the present study, selection of the OATP1B1 substrates for the in vitro
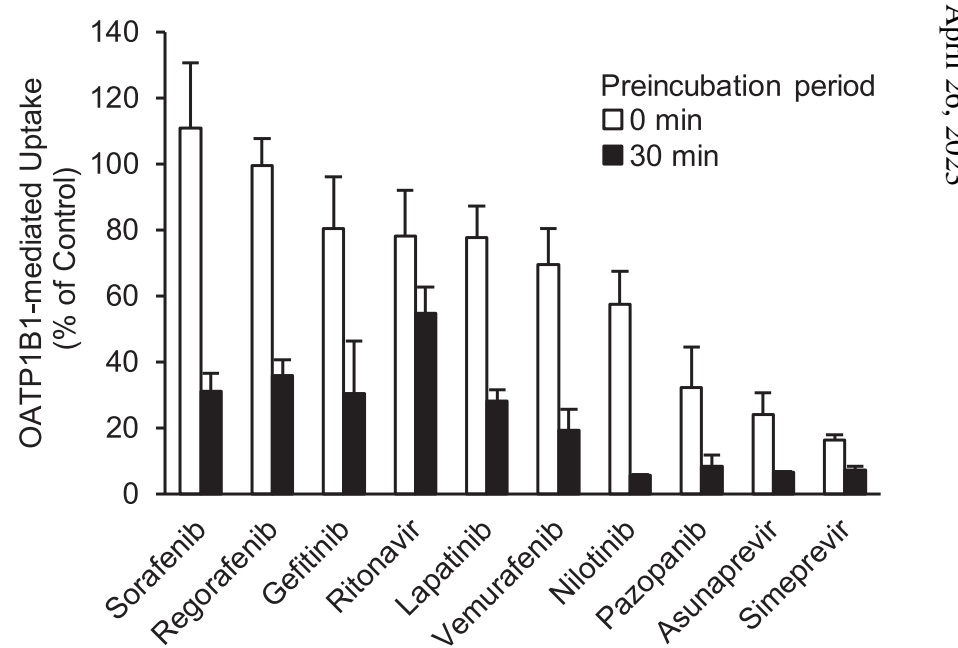

Fig. 5. Screening of preincubation-dependent OATP1B1 inhibitors. HEK293/ OATP1B1 and HEK293/mock cells were first preincubated with each compound at $1 \mu \mathrm{M}$ for 30 minutes (closed column) or subjected to no preincubation (open column). Cells were then incubated with ${ }^{3} \mathrm{H}_{\mathrm{H}} \mathrm{E}_{1} \mathrm{~S}$ and each compound for 0.5 minutes, followed by determination of OATP1B1-mediated uptake. Data are shown as the percentages of OATP1B1-mediated uptake obtained in the vehicle control samples of three wells in a single experiment. 


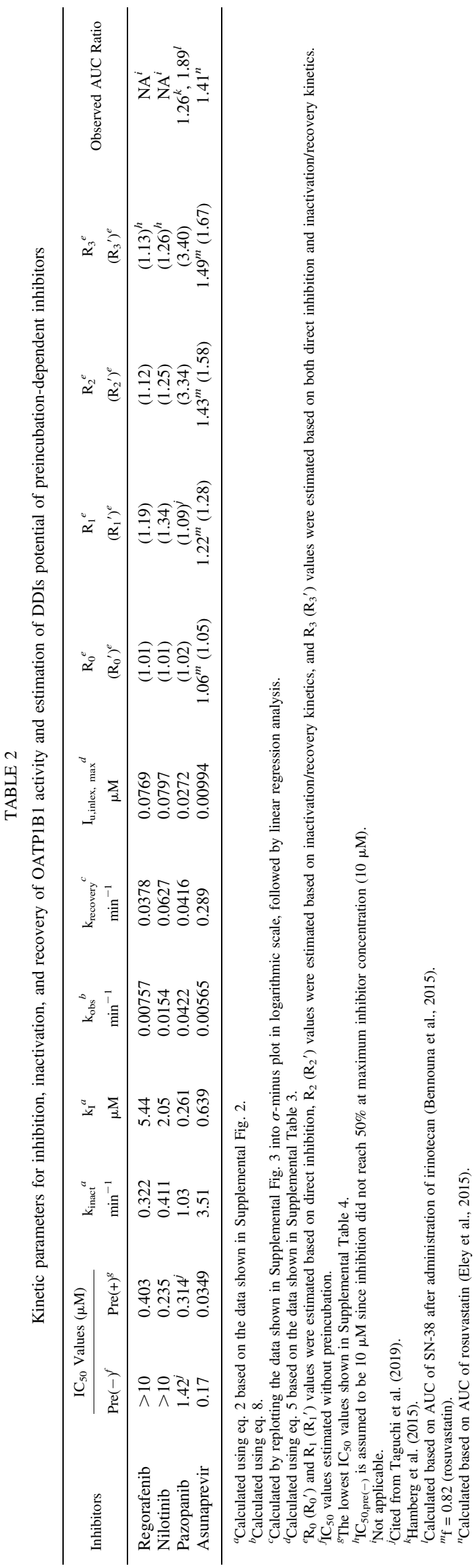

studies could be critical, and it would be preferable to select substrates that will concomitantly be used in clinical situations with the inhibitors examined. Additionally, $\mathrm{E}_{2} \mathrm{G}$ exhibited higher values of $R_{2}$ and $R_{3}$ when compared with $E_{1} S$ (Table 1), suggesting that $\mathrm{E}_{2} \mathrm{G}$ would be a superior substrate to avoid false-negative predictions among these two OATP1B1 substrates, although it should be noted that selection of the most-sensitive substrate, like $E_{2} G$, may increase the false-positive rate. The expression level of OATP1B1 was not affected by incubation with CsA, with no obvious change observed in its subcellular localization (Shitara et al., 2012), whereas the combination of cis- and trans-inhibition of OATP1B1 by CsA has been proposed to explain such preincubation-dependent inhibition (Shitara and Sugiyama 2017).

In the present study, $\mathrm{IC}_{50}$ values, but not inhibition constant $\left(\mathrm{K}_{\mathrm{i}}\right)$, were estimated for calculating the $\mathrm{R}$ values. Here, the $\mathrm{IC}_{50}$ values were assumed to be equal to $\mathrm{K}_{\mathrm{i}}$ values, as the substrate concentration used was much lower than the $\mathrm{K}_{\mathrm{m}}$ values. This assumption is true in the case of competitive or noncompetitive inhibition, whereas CsA exhibits preincubation-dependent inhibition, and therefore, the $\mathrm{IC}_{50}$ values may not be equal to the $K_{i}$ values even when the initial phase of substrate uptake was examined. Furthermore, inactivation of OATP1B1 activity induced by CsA was rapid (Fig. 2), and this may hinder the accurate estimation of $\mathrm{k}_{\text {inact }}$, especially at higher inhibitor concentrations. Thus, the static model proposed in the present study should be further validated and improved by focusing on other combinations of preincubationdependent inhibitors and substrates.

In conclusion, the static model incorporating both inactivation and recovery kinetics of OATP1B1 activity has been proposed to predict OATP1B1-mediated DDI potential for preincubation-dependent inhibitors. This approach would be beneficial for the quantitative prediction of DDIs when compared with the current basic model approach and to avoid false-negative predictions of the DDIs. However, the limitation of this approach regarding the precise estimation of DDI potential should be considered, especially in potent preincubation-dependent inhibition cases.

\section{Acknowledgments}

We would like to thank Masahiro Satsukawa (Kaken Pharmaceutical Co., Ltd.) for valuable discussions. We would also like to thank Yoshiyuki Sakai for performing the uptake experiments.

\section{Authorship Contributions}

Participated in research design: Taguchi, Masuo, Futatsugi, Kato.

Conducted experiments: Taguchi.

Performed data analysis: Taguchi.

Wrote or contributed to the writing of the manuscript: Taguchi, Masuo, Futatsugi, Kato.

\section{References}

Bennouna J, Deslandres M, Senellart H, de Labareyre C, Ruiz-Soto R, Wixon C, Botbyl J, Suttle $\mathrm{AB}$, and Delord JP (2015) A phase I open-label study of the safety, tolerability, and pharmacokinetics of pazopanib in combination with irinotecan and cetuximab for relapsed or refractory metastatic colorectal cancer. Invest New Drugs 33:138-147.

Duan P, Zhao P, and Zhang L (2017) Physiologically based pharmacokinetic (PBPK) modeling of pitavastatin and atorvastatin to predict drug-drug interactions (DDIs). Eur J Drug Metab Pharmacokinet 42:689-705.

Eley T, Han YH, Huang SP, He B, Li W, Bedford W, Stonier M, Gardiner D, Sims K, Rodrigues $\mathrm{AD}$, et al. (2015) Organic anion transporting polypeptide-mediated transport of, and inhibition by, asunaprevir, an inhibitor of hepatitis C virus NS3 protease. Clin Pharmacol Ther 97: $159-166$.

Fahmi OA, Hurst S, Plowchalk D, Cook J, Guo F, Youdim K, Dickins M, Phipps A, Darekar A, Hyland R, et al. (2009) Comparison of different algorithms for predicting clinical drug-drug interactions, based on the use of CYP3A4 in vitro data: predictions of compounds as precipitants of interaction. Drug Metab Dispos 37:1658-1666.

Fujita K, Sugiura T, Okumura H, Umeda S, Nakamichi N, Watanabe Y, Suzuki H, Sunakawa Y, Shimada K, Kawara K, et al. (2014) Direct inhibition and down-regulation by uremic plasma components of hepatic uptake transporter for SN-38, an active metabolite of irinotecan, in humans. Pharm Res 31:204-215. 
Furihata T, Matsumoto S, Fu Z, Tsubota A, Sun Y, Matsumoto S, Kobayashi K, and Chiba K (2014) Different interaction profiles of direct-acting anti-hepatitis C virus agents with human organic anion transporting polypeptides. Antimicrob Agents Chemother 58:4555-4564.

Ito K, Iwatsubo T, Kanamitsu S, Ueda K, Suzuki H, and Sugiyama Y (1998) Prediction of pharmacokinetic alterations caused by drug-drug interactions: metabolic interaction in the liver. Pharmacol Rev 50:387-412.

Iwase M, Fujita KI, Nishimura Y, Seba N, Masuo Y, Ishida H, Kato Y, and Kiuchi Y (2019) Pazopanib interacts with irinotecan by inhibiting UGT1A1-mediated glucuronidation, but not OATP1B1-mediated hepatic uptake, of an active metabolite SN-38. Cancer Chemother Pharmacol 83:993-998.

Izumi S, Nozaki Y, Kusuhara H, Hotta K, Mochizuki T, Komori T, Maeda K, and Sugiyama Y (2018) Relative activity factor (RAF)-based scaling of uptake clearance mediated by organic anion transporting polypeptide (OATP) 1B1 and OATP1B3 in human hepatocytes. Mol Pharm 15:2277-2288

Izumi S, Nozaki Y, Maeda K, Komori T, Takenaka O, Kusuhara H, and Sugiyama Y (2015) Investigation of the impact of substrate selection on in vitro organic anion transporting polypeptide 1B1 inhibition profiles for the prediction of drug-drug interactions. Drug Metab Dispos 43:235-247.

Kalliokoski A and Niemi M (2009) Impact of OATP transporters on pharmacokinetics. $\mathrm{Br}$ J Pharmacol 158:693-705.

Kunze A, Huwyler J, Camenisch G, and Poller B (2014) Prediction of organic anion-transporting polypeptide 1B1- and 1B3-mediated hepatic uptake of statins based on transporter protein expression and activity data. Drug Metab Dispos 42:1514-1521.

Maeda K (2015) Organic anion transporting polypeptide (OATP)1B1 and OATP1B3 as importan regulators of the pharmacokinetics of substrate drugs. Biol Pharm Bull 38:155-168.

Mayhew BS, Jones DR, and Hall SD (2000) An in vitro model for predicting in vivo inhibition of cytochrome P450 3A4 by metabolic intermediate complex formation. Drug Metab Dispos 28 1031-1037.

Pahwa S, Alam K, Crowe A, Farasyn T, Neuhoff S, Hatley O, Ding K, and Yue W (2017) Pretreatment with rifampicin and tyrosine kinase inhibitor dasatinib potentiates the inhibitory effects toward OATP1B1- and OATP1B3-mediated transport. J Pharm Sci 106:2123-2135.

Shitara Y and Sugiyama Y (2017) Preincubation-dependent and long-lasting inhibition of organic anion transporting polypeptide (OATP) and its impact on drug-drug interactions. Pharmaco Ther 177:67-80.
Shitara Y, Takeuchi K, and Horie T (2013) Long-lasting inhibitory effects of saquinavir and ritonavir on OATP1B1-mediated uptake. J Pharm Sci 102:3427-3435.

Shitara Y, Takeuchi K, Nagamatsu Y, Wada S, Sugiyama Y, and Horie T (2012) Long-lasting inhibitory effects of cyclosporin A, but not tacrolimus, on OATP1B1- and OATP1B3-mediated uptake. Drug Metab Pharmacokinet 27:368-378.

Sprowl JA, Ong SS, Gibson AA, Hu S, Du G, Lin W, Li L, Bharill S, Ness RA, Stecula A, et al (2016) A phosphotyrosine switch regulates organic cation transporters. Nat Commun 7:10880.

Taguchi T, Masuo Y, Kogi T, Nakamichi N, and Kato Y (2016) Characterization of Long-Lasting Oatp Inhibition by Typical Inhibitor Cyclosporine A and In Vitro-In Vivo Discrepancy in Its Drug Interaction Potential in Rats. J Pharm Sci 105:2231-2239.

Taguchi T, Masuo Y, Sakai Y, and Kato Y (2019) Short-lasting inhibition of hepatic uptake transporter OATP1B1 by tyrosine kinase inhibitor pazopanib. Drug Metab Pharmacokinet 34 372-379.

Vaidyanathan J, Yoshida K, Arya V, and Zhang L (2016) Comparing various in vitro prediction criteria to assess the potential of a new molecular entity to inhibit organic anion transporting polypeptide 1B1. J Clin Pharmacol 56 (Suppl 7):S59-S72.

Yamaoka K, Tanigawara Y, Nakagawa T, and Uno T (1981) A pharmacokinetic analysis program (multi) for microcomputer. J Pharmacobiodyn Actions 4:879-885.

Yoshida K, Maeda K, and Sugiyama Y (2012) Transporter-mediated drug--drug interactions involving OATP substrates: predictions based on in vitro inhibition studies. Clin Pharmacol Ther 91:1053-1064.

Yoshimatsu H, Konno Y, Ishii K, Satsukawa M, and Yamashita S (2016) Usefulness of minipigs for predicting human pharmacokinetics: Prediction of distribution volume and plasma clearance. Drug Metab Pharmacokinet 31:73-81.

Zhang Y, Panfen E, Fancher M, Sinz M, Marathe P, and Shen H (2019) Dissecting the contribution of OATP1B1 to hepatic uptake of statins using the OATP1B1 selective inhibitor estropipate. Mol Pharm 16:2342-2353.

Address correspondence to: Dr. Yukio Kato, Faculty of Pharmacy, Institute of Medical, Pharmaceutical and Health Sciences, Kanazawa University, Kakumamachi, Kanazawa 920-1102, Japan. E-mail: ykato@p.kanazawa-u.ac.jp 